\title{
Enhanced trypsin thermostability in Pichia pastoris through truncating the flexible region
}

\author{
Lin Liu ${ }^{1,2,3}$, Haoran Yu $u^{1,2,3,4}$, Kun Du ${ }^{1,2,3}$, Zhiyan Wang ${ }^{1,2,3}$, Yiru Gan ${ }^{1,2,3}$ and He Huang ${ }^{1,2,3^{*}}$
}

\begin{abstract}
Background: High thermostability is required for trypsin to have wider industrial applications. Target mutagenesis at flexible regions has been proved to be an efficient protein engineering method to enhance the protein thermostability.

Results: The flexible regions in porcine trypsin were predicted using the methods including molecular dynamic simulation, FlexPred, and FoldUnfold. The amino acids 78-90 was predicted to be the highly flexible region simultaneously by the three methods and hence selected to be the mutation target. We constructed five variants (D3, D5, D7, $\mathrm{D} 9$, and D11) by truncating the region. And the variant D9 showed higher thermostability, with a $5^{\circ} \mathrm{C}$ increase in $T_{\text {opt' }}$ $5.8^{\circ} \mathrm{C}$ rise in $T_{50}^{10}$, and a $4.5^{\circ} \mathrm{C}$ rise in $T_{m^{\prime}}$ compared to the wild-type. Moreover, the half-life value of the variant D9 was also found to be dramatically improved by $46 \mathrm{~min}$. Circular dichroism and intrinsic fluorescence indicated that the structures had no significant change between the variant D9 and the wild-type. The surface hydrophobicity of D9 was measured to be lower than that of wild-type, indicating the increased hydrophobic interaction, which could have contributed to the improved thermostability of D9.
\end{abstract}

Conclusions: These results showed that the thermostability of variant D9 was increased. The variant D9 could be expected to be a promising tool enzyme for its wider industrial applications. The method of truncating the flexible region used in our study has the potential to be used for enhancing the thermostability of other proteins.

Keywords: Thermostability, Trypsin, Flexible region, Truncation, $\Omega$-loop

\section{Background}

Trypsin (EC 3.4.21.4) is a serine protease, which hydrolyzes peptide bonds on the carboxylic sides of lysine and arginine [1]. It exists widely in nature, and has been discovered in bacteria, fungus and mammals [2]. As an essential tool enzyme, trypsin can be applied in variety of fields including pharmaceutical, leather processing, and food processing, especially in proteomic applications about the use of mass spectrometry (MS) to analyze the peptides obtained $[3,4]$. The peptides must be denatured to achieve effective digestion, since the native peptide could not be digested by trypsin. However, the peptides denatured by chemicals would complicate the further analytical steps. The problem could be solved by

\footnotetext{
${ }^{*}$ Correspondence: huang@tju.edu.cn

${ }^{3}$ Collaborative Innovation Center of Chemical Science and Engineering,

Tianjin 300350, China

Full list of author information is available at the end of the article
}

hydrolyzing peptides under high temperature conditions. Therefore, it is necessary to improve the thermostability of trypsins for satisfying the industrial applications.

In recent years, a number of effective approaches, such as enzyme immobilization, protein engineering, and use of cosolvents, have been successfully utilized to improve the thermostability of trypsin [5-7]. For example, Pazhang et al. reported that polyols (sorbitol and glycerol) stabilized trypsin by decreasing the polypeptide chain fluctuations. Among various methods from improving protein stability, the protein engineering attracted more attention due to requiring changes to the primary structure of the enzyme to confer the desired features [8]. Up to date, protein engineering comprises two main approaches including directed evolution and rational design. The process of directed evolution is heavily experimental and time-consuming. And highthroughput screening is usually required in directed evolution. However, not all enzyme stabilities are amenable 
to developing a high-throughput screening method. Recently, rational design has been widely applied for engineering the protein thermostability. Compared to directed evolution, rational design is faster and universal because it focuses more on several specific target sites.

With flexible sites as target sites, the strategy of RFS (rigidifying flexible sites) has been a powerful method to engineer the protein thermostability [9]. Identifying the flexible regions was the critical procedure for designing thermostable proteins using this strategy. Molecular dynamics (MD) simulation was commonly applied to identify the highly flexible regions of proteins. However, disadvantages, such as computational expense and inaccuracy, limit the use of MD simulation [10]. Two other methods (FlexPred and FoldUnfold) could also be used to precisely predict the flexible regions, which are faster and cheaper than the MD simulation [11]. When the three methods are used in combination, it has the potential to be more effective to find the highly flexible region.

Rigidifying the flexible regions was another step in the RFS strategy for engineering the protein thermostability [9]. Among various approaches applied to rigidify the flexible regions, the method of truncating flexible regions has received attention in recent years [12-14]. Ban reported that truncation of a flexible portion of the C-terminal end in $\mathrm{GBE}_{G t}$ (1,4- $\alpha$-glucan branching enzyme from G. thermoglucosidans STB02) enhanced the thermostability of the enzyme without significantly compromising its enzyme activity [15]. Truncating the flexible $\mathrm{N}$-terminal contributed to increasing thermal stability of mannanase Man 1312 without activity loss [16]. Thus, it is possible to enhance the thermal stability of proteins through truncating the flexible regions.

$\Omega$-loop, a nonregular secondary structure, commonly connects $\alpha$-helices and $\beta$-strands [17]. As a special loop, $\Omega$-loop usually consists of $6-16$ amino acids and locates on the surface of proteins, which plays essential roles in protein folding, function and stability [18]. Structural analysis of psychrophilic, mesophilic and thermophilic enzymes revealed that shorter and fewer surface loops are usually existed in thermophilic enzymes due to the higher structural rigidity [19]. Thompson et al. found that the thermostability of proteins could be improved by deleting the dynamic surface loop [20]. Similarly, the thermostability of HCA II could be improved through truncating the surface loop [21]. Therefore, truncation could be an effective way to rigidify the flexible loop and improve the thermostability of trypsin.

In this study, we aimed to enhance the thermostability of the trypsin expressed in Pichia pastoris GS115 using the strategy of RFS. MD simulation, FlexPred, and FoldUnfold were firstly used to predict the highly flexible regions. It was found that the predicted flexible region (amino acids 78-90) was overlapped with the $\Omega$-loop region (amino acids 78-91) (Figs. 1, 2a). Five variants were constructed by truncating the flexible $\Omega$-loop. The effects of loop truncation on the kinetic properties, thermostability and structural properties were determined. The best variant (D9) showed significantly improved thermal stability without compromising enzymatic activity.

\section{Results}

\section{Design and purification of the trypsin variants}

In this study, we attempted to enhance the thermostability of trypsin by the approach of rational design. The flexible regions were predicted by three methods (MD simulation, FoldUnfold, and FlexPred) and listed (Additional file 1: Fig. S1 and Table S1). We selected four flexible regions from each method and compared with each other. The amino acids 78-90 was predicted to be the highly flexible region of the trypsin, which is overlapped with the $\Omega$-loop region (amino acids 78-91) (Figs. 1, 2a). The $\Omega$-loop (amino acids 78-91) was placed between the two short $\beta$-strands based on the analysis of three-dimensional porcine trypsin structure, which seemingly interrupts the formation of one long strand. Moreover, based on previous reports, loops were generally considered as potential targets for engineering proteins with improved properties [13, 22-24]. Then five variants (D3, D5, D7, D9, and D11) were designed by truncating the flexible loop by three residues (D3), five residues (D5), seven residues (D7), nine residues (D9) and eleven residues (D11) (Fig. 2b, Additional file 1: Fig. S2). A SP-Sepharose column was used for purifying the variants. The results of SDS-PAGE indicated that all purified enzymes showed a single band of $\sim 24 \mathrm{kDa}$ (Fig. 3).

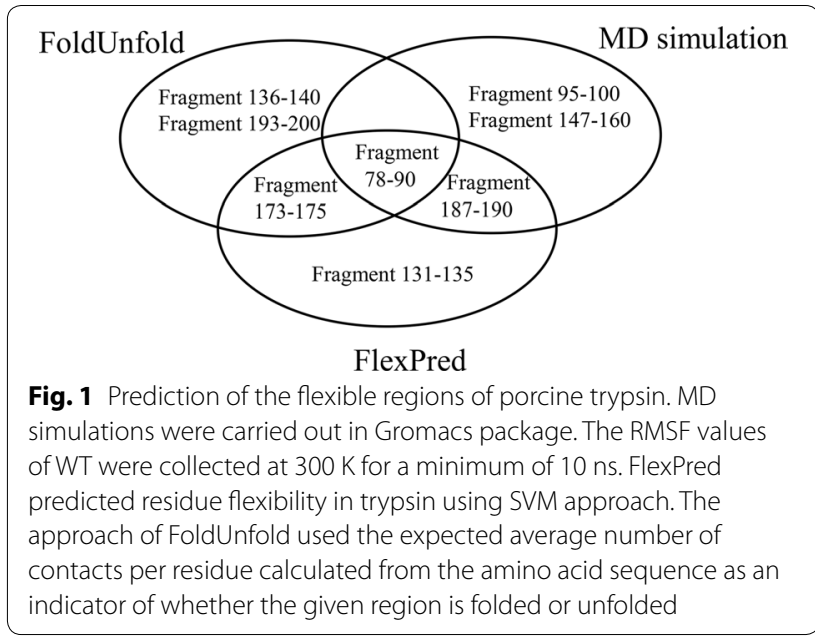




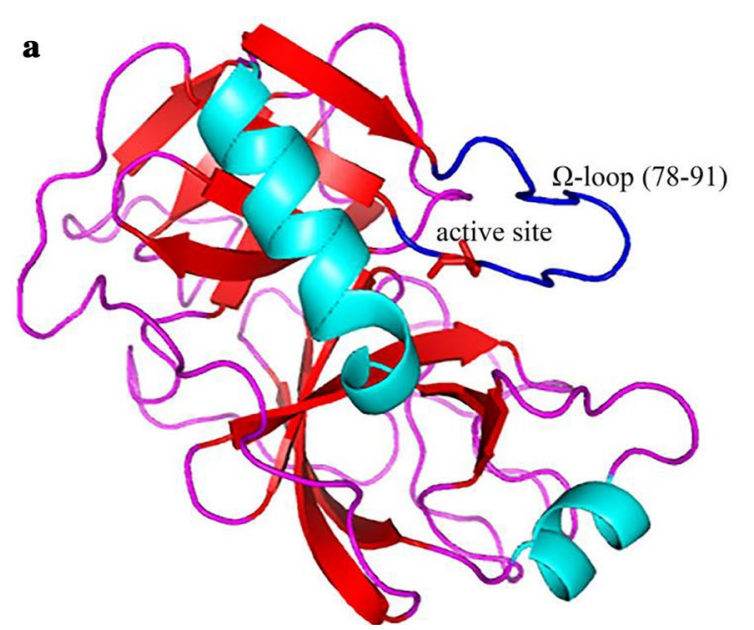

b

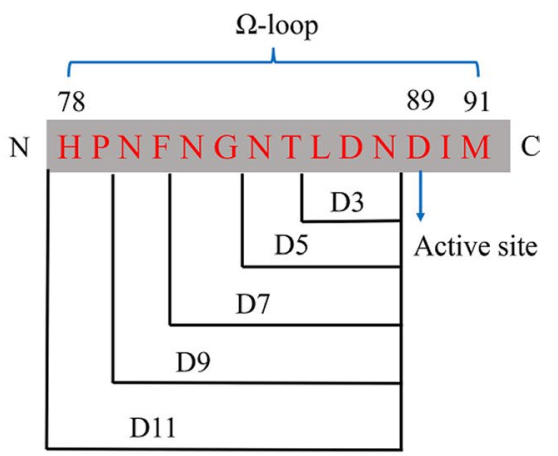

Fig. 2 Design of the truncation of the $\Omega$-loop region. a Crystal structure of porcine trypsin visualized by the PyMOL software from the Protein Data Bank (PDB ID: 4AN7). The $\Omega$-loop is colored blue and the active site is colored red. $\mathbf{b}$ The design of the truncation of the $\Omega$-loop region

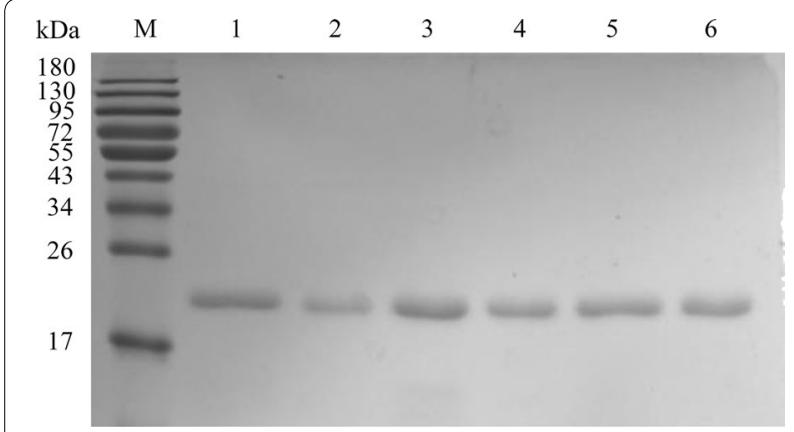

Fig. 3 SDS-PAGE analysis for purified WT and variants (D3, D5, D7, D9, and D11) $(10 \mu \mathrm{L}$; protein concentration $3 \mu \mathrm{g}) . \mathrm{M}$, molecular weight marker; 1, WT; 2-6, D3, D5, D7, D9, and D11

Furthermore, we measured the protein yield based on the purified enzymes. The protein yield of WT was $43.32 \mathrm{mg} / \mathrm{L}$, while the yields of D3, D5, D7, D9, and D11 were $25.82 \mathrm{mg} / \mathrm{L}, 29.92 \mathrm{mg} / \mathrm{L}, 53.44 \mathrm{mg} / \mathrm{L}, 40.58 \mathrm{mg} / \mathrm{L}$, and $33.49 \mathrm{mg} / \mathrm{L}$, respectively. Apparently, the protein yields of other variants were lower than that of WT except for D7. The results suggested that the protein yield might be influenced after truncating the flexible region of trypsin.

\section{Analysis of thermostability properties}

The term "protein stability" commonly includes kinetic stability and thermodynamic stability [25]. To investigate kinetic stability of WT and variants, purified enzymes were incubated at $50^{\circ} \mathrm{C}$ for different time $(30 \mathrm{~min}, 60 \mathrm{~min}$, $90 \mathrm{~min}, 120 \mathrm{~min}$, and $180 \mathrm{~min}$, respectively) and then the residual activity was measured at $25{ }^{\circ} \mathrm{C}$. The effect of the heat treatment on enzyme activities was shown in Fig. 4 and Table 1 . The $k_{\mathrm{d}}$ values of variants were lower than that of WT except D11, indicating that WT had deactivated more slowly than D11 and more rapidly than other variants. After incubation at $50{ }^{\circ} \mathrm{C}$ for $60 \mathrm{~min}, \mathrm{WT}, \mathrm{D} 7$ and $\mathrm{D} 9$ had $70 \%$ remaining activities, while the residual activity of D11 was nearly 60\% (Additional file 1: Fig. S3). Meanwhile, both variants D3 and D5 retained more than $85 \%$ of the original activities. The half-life value of WT was $155.76 \mathrm{~min}$, while the half-life times of D3, D5. D7, D9, and D11 were $209.41 \mathrm{~min}, 199.18 \mathrm{~min}, 171.57 \mathrm{~min}$, $202.08 \mathrm{~min}$, and $124.44 \mathrm{~min}$, respectively (Table 1). Except D11, all other variants showed longer half-life time than WT, indicating that the kinetic stability of trypsin was improved by truncating the $\Omega$-loop region.

The inactivation curves of WT and variants were obtained by incubating the enzymes at temperatures ranging from 25 to $85{ }^{\circ} \mathrm{C}$ for $10 \mathrm{~min}$. After heat treatment, enzymes were cooled in the icebox for $5 \mathrm{~min}$. As shown in Fig. 5a, WT almost lost their enzyme activities at $85^{\circ} \mathrm{C}$, but other variants remained nearly $15 \%$ of its original activity. Moreover, the residual activity of all variants at $60^{\circ} \mathrm{C}$ was above $50 \%$, while WT only retained $20 \%$ of initial activity. The $T_{50}^{10}$ values of $\mathrm{D} 3, \mathrm{D} 5, \mathrm{D} 7, \mathrm{D} 9$, and $\mathrm{D} 11$ were determined to be $65.8{ }^{\circ} \mathrm{C}, 62.0{ }^{\circ} \mathrm{C}, 61.2^{\circ} \mathrm{C}, 60.3^{\circ} \mathrm{C}$, and $60.5{ }^{\circ} \mathrm{C}$, respectively, while that of WT was $54.5^{\circ} \mathrm{C}$ (Table 1 ).

\section{Melting temperature measurement}

To investigate the effect of truncation on the thermodynamic stability, the thermoflour assay using the SYPRO Orange as a dye was determined. SYPRO Orange is weakly fluorescent in the hydrophilic environment but has a high fluorescence intensity in hydrophobic regions of proteins [26]. Along with the protein unfolding, the 


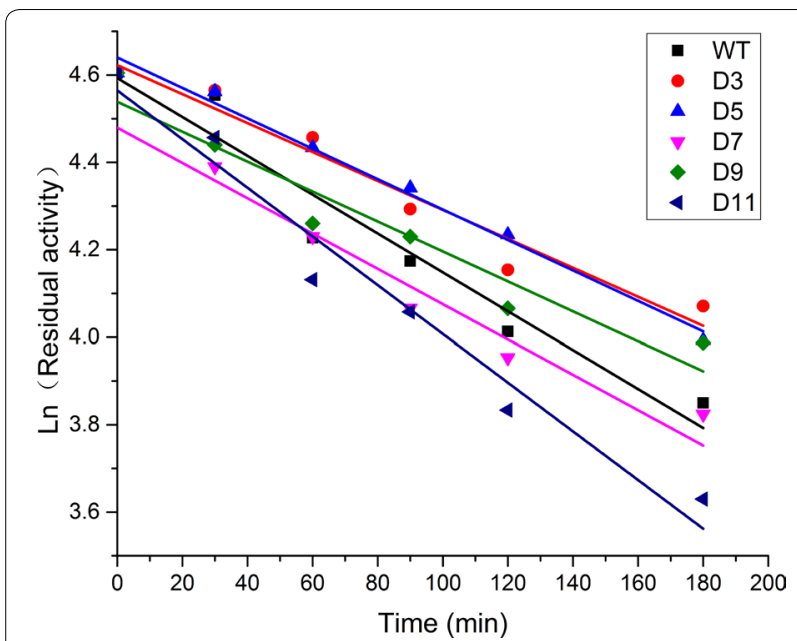

Fig. 4 Natural-logarithmic plot of residual activity of WT and variants (D3, D5, D7, D9, and D11). After incubation at $50^{\circ} \mathrm{C}$ for different minutes, the residual activity of each trypsin was assayed. The original activity was defined as $100 \%$. Each value is the mean of three independent experiments

Table 1 Thermostability constants of WT and variants

\begin{tabular}{llllll}
\hline Enzymes & $\boldsymbol{T}_{\text {opt }}\left({ }^{\circ} \mathbf{C}\right)$ & $\boldsymbol{T}_{\mathbf{m}}\left({ }^{\circ} \mathbf{C}\right)$ & $\boldsymbol{T}_{\mathbf{5 0}}^{\mathbf{1 0}}\left({ }^{\circ} \mathbf{C}\right)$ & $\boldsymbol{t}_{\mathbf{1 / 2}}\left(\mathbf{5 0}{ }^{\circ} \mathbf{C}\right)(\mathbf{m i n})$ & $\boldsymbol{k}_{\mathbf{d}}\left(\mathbf{m i n}^{-\mathbf{1}}\right)$ \\
\hline WT & 60.0 & 51.0 & 54.5 & 155.76 & $4.45 \times 10^{-3}$ \\
D3 & 65.0 & 50.5 & 65.8 & 209.41 & $3.31 \times 10^{-3}$ \\
D5 & 60.0 & 62.3 & 62.0 & 199.18 & $3.48 \times 10^{-3}$ \\
D7 & 55.0 & 54.4 & 61.2 & 171.57 & $4.04 \times 10^{-3}$ \\
D9 & 65.0 & 55.5 & 60.3 & 202.08 & $3.43 \times 10^{-3}$ \\
D11 & 50.0 & 53.3 & 60.5 & 124.44 & $5.57 \times 10^{-3}$ \\
\hline
\end{tabular}

Each value was calculated from triplicate experiments

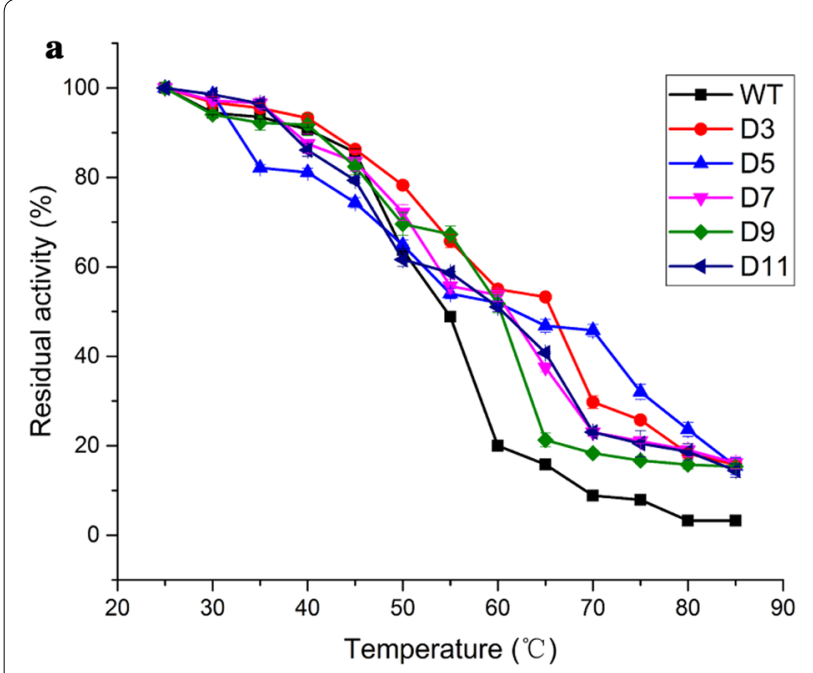

dye binds to the exposed hydrophobic regions of the protein which could lead to a significant increase in the fluorescence intension. As shown in Table 1 and Additional file 1: Fig. S4, $T_{\mathrm{m}}$ value for WT was $51.0{ }^{\circ} \mathrm{C}$, whereas $T_{\mathrm{m}}$ values of variants were $50.5{ }^{\circ} \mathrm{C}, 62.3{ }^{\circ} \mathrm{C}, 54.4{ }^{\circ} \mathrm{C}, 55.5^{\circ} \mathrm{C}$, and $53.3{ }^{\circ} \mathrm{C}$ for D3, D5, D7, D9, and D11, respectively. The thermodynamic stability of variants of D5, D7, D9, and D11 was higher than that of WT, while the thermodynamic stability of D3 was decreased.

\section{Optimum temperature for WT and variants}

The influence of temperature on the enzymatic activity of WT and variants was investigated. The enzyme activity profile was measured between 25 and $85^{\circ} \mathrm{C}$, with $5{ }^{\circ} \mathrm{C}$ intervals. As shown in Fig. $5 \mathrm{~b}$ and Table 1, the optimum temperatures of D3 and $\mathrm{D} 9$ were $65{ }^{\circ} \mathrm{C}, 5{ }^{\circ} \mathrm{C}$ higher than that of WT, while the optimum temperatures of D7 and D11 were decreased by $5{ }^{\circ} \mathrm{C}$ and $10{ }^{\circ} \mathrm{C}$, respectively. The optimum temperature of D5 was $60^{\circ} \mathrm{C}$, which was consistent with that of WT. At $85^{\circ} \mathrm{C}$, the variant D9 retained nearly $30 \%$ of its initial activity, while the residual activity of other variants and WT was about $15 \%$.

\section{Characterization of kinetic properties}

Kinetic parameters of WT and variants were shown in Table 2. The $K_{\mathrm{m}}$ and $k_{c a t}$ values of WT were $28.80 \pm 2.94 \mu \mathrm{M}$ and $0.634 \pm 0.030 \mathrm{~s}^{-1}$, respectively. The $K_{\mathrm{m}}$ values of D7 and D11 were drastically decreased, and that of D3 was increased by more than $50 \%$. Furthermore, the $K_{\mathrm{m}}$ values of D5 and D9 were $33.40 \pm 4.11 \mu \mathrm{M}$ and $27.04 \pm 3.35 \mu \mathrm{M}$, respectively. Although $k_{\text {cat }}$ values displayed no significant difference between WT and

Fig. 5 Thermostability properties of WT and variants (D3, D5, D7, D9, and D11). a Comparison of thermal tolerance for WT and variants. The residual activities of the enzymes were measured after incubating at different temperatures $\left(25-85^{\circ} \mathrm{C}\right)$ for $10 \mathrm{~min}$. $\mathbf{b}$ Effect of temperature on enzyme activity. The residual activities were determined under different temperatures $\left(25-85^{\circ} \mathrm{C}\right)$. Values are presented as the average of three experiments 
Table 2 Kinetic parameters of WT and variants

\begin{tabular}{lllcr}
\hline Enzymes & $\boldsymbol{K}_{\mathbf{m}}(\boldsymbol{\mu M})$ & $\boldsymbol{k}_{\text {cat }}\left(\mathbf{s}^{\mathbf{- 1}}\right)$ & $\boldsymbol{k}_{\text {cat }} / \boldsymbol{K}_{\mathbf{m}}\left(\mathbf{m M}^{-\mathbf{1}} \mathbf{s}^{\mathbf{- 1}}\right)$ & Specific activity $(\mathbf{U} / \mathbf{m g})$ \\
\hline WT & $28.80 \pm 2.94$ & $0.634 \pm 0.030$ & $22.014 \pm 1.45$ & $105,614.2 \pm 4154.28$ \\
D3 & $58.60 \pm 3.30$ & $0.676 \pm 0.007$ & $11.536 \pm 0.87$ & $73,850.3 \pm 1385.34$ \\
D5 & $33.40 \pm 4.11$ & $0.652 \pm 0.007$ & $19.521 \pm 1.05$ & $102,234.8 \pm 5238.41$ \\
D7 & $11.01 \pm 0.94$ & $0.604 \pm 0.024$ & $54.910 \pm 3.56$ & $196,961.5 \pm 8182.93$ \\
D9 & $27.04 \pm 3.35$ & $0.624 \pm 0.099$ & $23.111 \pm 2.19$ & $108,760.9 \pm 5205.32$ \\
D11 & $7.50 \pm 0.29$ & $0.580 \pm 0.019$ & $77.330 \pm 4.98$ & $340,425.6 \pm 9314.77$ \\
\hline
\end{tabular}

Each value was calculated from triplicate experiments. Means \pm standard deviations

The enzyme activities were measured at $25^{\circ} \mathrm{C}$

variants, the $k_{\text {cat }} / K_{\mathrm{m}}$ values of D7 and D11 were around $150 \%$ and $250 \%$ higher than that of WT, respectively. In addition, the $k_{\text {cat }} / K_{\mathrm{m}}$ value of D3 was decreased by nearly $50 \%$, while other variants showed no considerable change compared with WT. The specific activity of WT was $105,614.2 \pm 4154.28 \mathrm{U} / \mathrm{mg}$, while the specific activity of D3, D5, D7, D9, and D11 was 73,850.3 $\pm 1385.34 \mathrm{U} / \mathrm{mg}$, $102,234.8 \pm 5238.41 \mathrm{U} / \mathrm{mg}, 196,961.5 \pm 8182.93 \mathrm{U} / \mathrm{mg}$, $108,760.9 \pm 5205.32 \mathrm{U} / \mathrm{mg}$, and $340,425.6 \pm 9314.77 \mathrm{U} /$ $\mathrm{mg}$, respectively (Table 2 ). The specific activity of trypsin displayed the same tendency of changes with the catalytic efficiency after truncating the $\Omega$-loop region.

\section{CD spectroscopy analysis}

$\mathrm{CD}$ spectra and fluorescence spectra were performed to further explore the impact of the truncation on structures. As shown in Fig. 6, CD spectra of WT and all variants exhibited a similar shape. The spectrum of WT and its variants all showed a single negative band near to $205 \mathrm{~nm}$, indicating that the percentage of the secondary structure had no considerable alteration (Additional file 1: Table S2).

\section{Fluorescence spectroscopy analysis}

Intrinsic fluorescence experiment was carried out to estimate the influence of mutations on the tertiary structure of trypsin. As shown in Fig. 7a, except for D11, the result of fluorescence spectra displayed that WT and other variants had a maximum emission at around $334 \mathrm{~nm}$. It indicated that there was no significant change in tertiary structures after the truncation the $\Omega$-loop region. However, a redshift of $3 \mathrm{~nm}$ was found between WT and D11, which indicated partial tryptophan residues of D11 more exposed to the hydrophilic environment. In addition, the emission intensity of D3, D5, D7, and D9 were notably higher than that of WT, suggesting that the tryptophan residues were buried away from the aqueous solvent.

The surface hydrophobicity of trypsin was determined by fluorescence spectra. As shown in Fig. 7b, the fluorescence intensity of WT was higher than variants (D5, D7, and D9). The results indicated that the three variants had

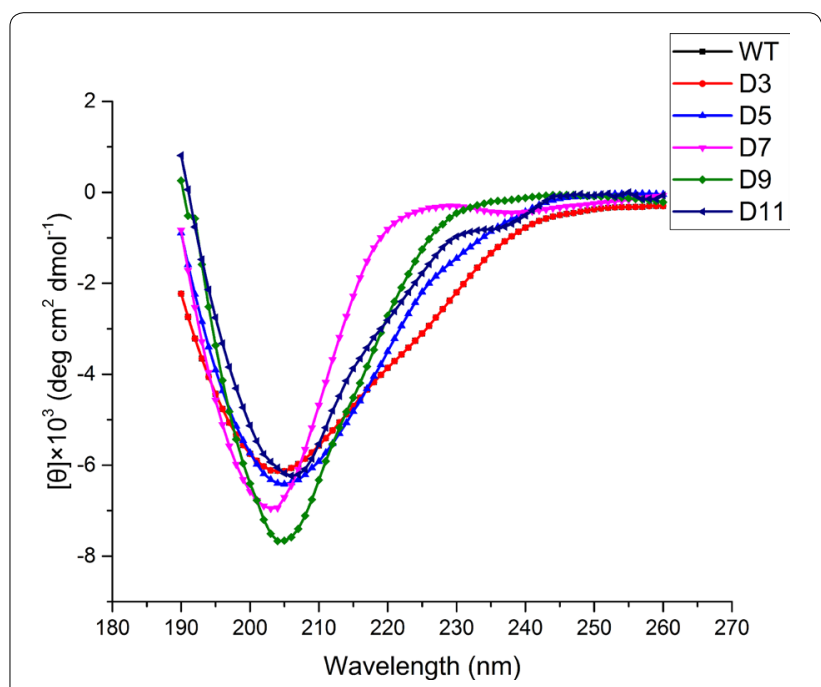

Fig. 6 CD spectra of WT and variants (D3, D5, D7, D9, and D1 1) were measured at room temperature $\left(25^{\circ} \mathrm{C}\right)$. The concentration of protein used for the far-UV CD spectrum (190-260 nm) was $0.2 \mathrm{mg} / \mathrm{mL}$. Each enzyme equilibrated in Tris-HCl buffer (10 mM, pH 8.0)

a significant decrease in the surface hydrophobicity compared with WT.

\section{Discussion}

Trypsin is the most widely used protease for the studies about proteins. In many instances, a high thermostability of trypsin is usually required in some industrial and biotechnological applications. Some methods, such as immobilization, the addition of polyol and enzymatic glycation, have been used for improving the thermostability of trypsin $[6,27,28]$. In the present study, we improved the thermostability of trypsin by truncating the flexible region. The highly flexible region (amino acids 78-90) was identified, which is overlapped with the $\Omega$-loop region (amino acids 78-91). We designed five variants (D3, D5, D7, D9, and D11) in this flexible loop. Among these variants, D9 variant showed significantly improved thermostability with no loss of enzyme activity. In addition, the variant D9 showed no significant change in structures 

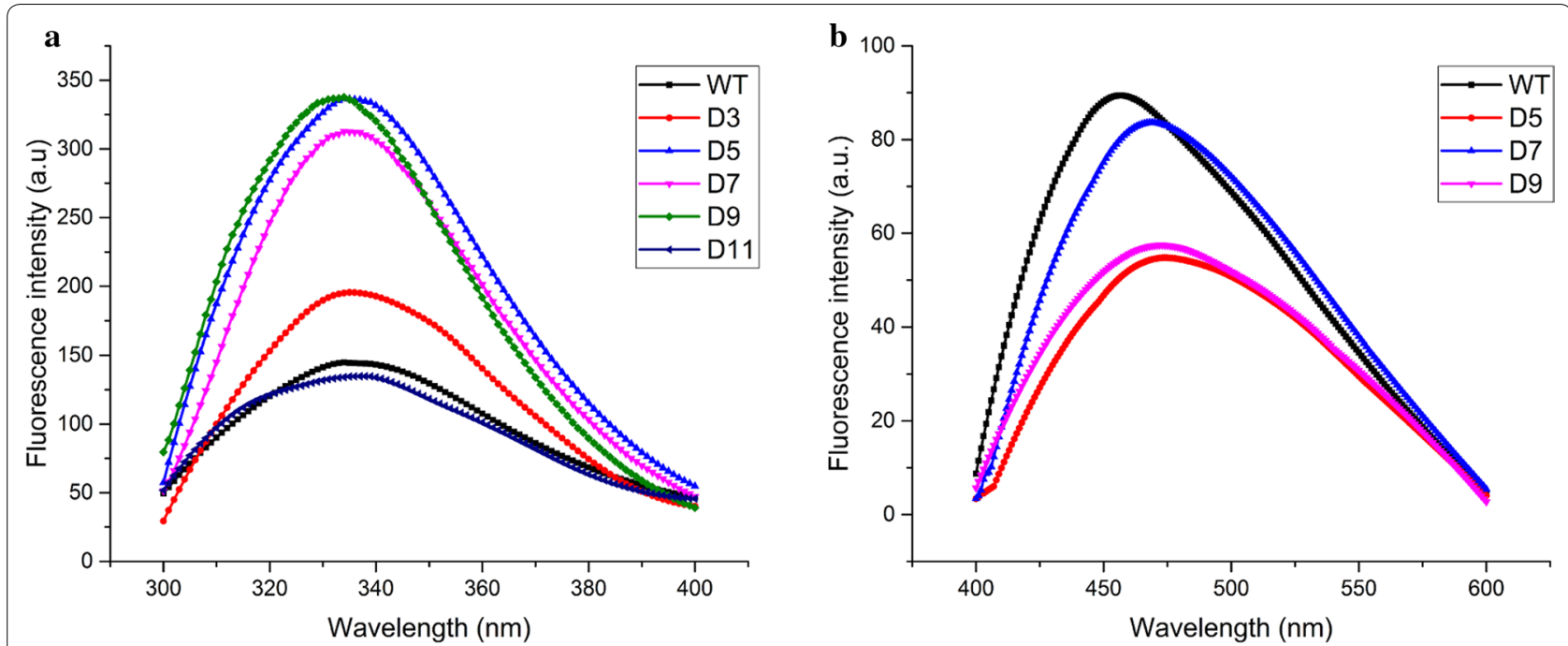

Fig. 7 Fluorescence spectra of WT and variants (D3, D5, D7, D9, and D11). a Intrinsic fluorescence spectra of WT and variants. The fluorescence emission spectra were monitored at $300-400 \mathrm{~nm}$. b Surface hydrophobicity of WT and variants. The fluorescence emission spectra were recorded between 400 and $600 \mathrm{~nm}$

when comparing with WT. The properties of D9 suggest that truncating the flexible regions could be an effective strategy for improving the thermostability of proteins.

In this work, MD simulation was used to determine the overall and local flexibility of WT and D9 variant. The overall flexibility of proteins was evaluated using RMSD values. And the local flexibility of proteins was investigated by analyzing the RMSF values. As shown in Additional file 1: Figs. S5, S6, the variant D9 showed lower RMSD and RMSF values compared with WT. From the results, we found that the overall and local flexibility of D9 variant were all decreased, which might be a reason that the thermostability of D9 variant was increased. Previous studies have showed that the proteins with better thermostability which usually displayed higher rigidity $[9,29]$. Furthermore, we also predicted the residue fluctuation profile by submitting the protein structures to CABS-flex sever. As shown in Additional file 1: Fig. S7, the $\Omega$-loop located at a region with high mobility, suggesting that these residues in this region underwent large disturbance. And the fluctuations in this region were considerably alleviated when the $\Omega$-loop was truncated. This result might be related to the enhancement of the hydrophobic interaction in variant D9. Hydrophobic interaction plays an essential role in the stability of protein structure [30]. Due to the energetic cost of solvating nonpolar side chains, the exposure of hydrophobic residues at the protein surface may lead to a decrease in protein thermostability [31]. The increase in the hydrophobicity of protein's internal residues or the decrease in the hydrophobicity of protein's surface residues improves the hydrophobic interaction of proteins $[32,33]$. In this study, the surface hydrophobicity of D9 was lower than that of WT, indicating the increased hydrophobic interaction.

Enhancing stability without sacrificing enzyme activity is critical for protein engineering [34]. The improvement of thermostability generally leads to the decrease of enzyme activity due to the so-called stability-activity trade-off [35]. As shown in Table 2, we observed that the change in enzyme activity was mainly caused by an alteration of the $K_{\mathrm{m}}$ value but not the $k_{\text {cat }}$ value. The thermostability of D3 was significantly increased, while the catalytic efficiency of D3 was decreased by nearly $50 \%$ compared with WT. The $K_{\mathrm{m}}$ of D3 was increased by 1.03 -fold, indicating that the substrate binding affinity was affected after deleting the three residues at the $\Omega$-loop region. In contrast, the variant D11 has the lowest melting temperature and shortest halflife among these variants. The $K_{\mathrm{m}}$ of D11 was drastically decreased and its $k_{\text {cat }}$ value was decreased only slightly, resulting in the highest catalytic efficiency (Table 2). The reason for this might be the change of surface charge between WT and D11 (Additional file 1: Fig. S8). Vidya et al. found that the alteration of surface charge affected the thermal properties of L-asparaginase II [36]. And Niu et al. reported that the variant BglT with high activities displayed the biased distribution of surface charge compared with the wild-type BglT [29]. In this research, we investigated the electrostatic surfaces of WT and D11 using PyMOL. The potential distribution of WT exhibited neutral in the $\Omega$-loop region, while the variant D11 displayed almost all negative in this region. Furthermore, we inferred that the decrease of thermostability of D11 might be related to the loss of aromatic $\pi-\pi$ interactions. The aromatic $\pi-\pi$ interaction plays an important role in 
protein stability and the loss of aromatic $\pi-\pi$ interaction could decrease the protein stability. For instance, Deng et al. found that aromatic $\pi-\pi$ interaction was more powerful than hydrogen bonds and salt bridges in stabilizing $\alpha$-amylase [37]. Thus, we analyzed aromatic $\pi-\pi$ interactions of D11 by PIC server, and it revealed that the variant D11 lacked three aromatic $\pi-\pi$ interactions when compared with WT. Nevertheless, the activity-stability tradeoff could be overcome through creating chemically and/ or genetically modified nonnatural enzymes [19]. In this study, the thermostability and catalytic efficiency of D9 are all increased compared with WT. Based on the crystal structure, we found the active site of Asp89 was located at the $\Omega$-loop region (Fig. 2a). The active site was usually covered by the adjacent loops, which might influence the enzyme activity [38]. Moreover, Zhang et al. reported that rigidifying the flexible residues in the active center improved the thermostability of Candida rugosa lipase1, without a decrease in catalytic activity [39]. Thus, truncating the $\Omega$-loop region might result in the improvement of the thermostability and enzyme activity at the same time.

$\mathrm{CD}$ spectra and fluorescence spectra were measured to investigate the structural changes between the WT and variants. Compared with $\mathrm{WT}$, the $\mathrm{CD}$ spectra of all variants showed no obvious change. It indicated the truncation of the $\Omega$-loop region have almost no influence on the secondary structure of trypsin. Moreover, according to the results of fluorescence experiments, the intrinsic fluorescence intensity of variants (D3, D5, D7, and D9) showed a superior increase compared with WT, suggesting the structure of enzyme became tighter after truncating the $\Omega$-loop region. This result was coincident with the work of Kheirollahi and Khajeh [34]. They found that the higher intrinsic fluorescence intensity might be the result of the increase of structure compactness in the variant Glu138Pro. Moreover, Boone et al. suggested that the thermal stability of HCA II can be increased by improving the surface compactness via loop truncation [21].

Accurate prediction of flexible regions is critical for engineering the thermostability of proteins through the method of RFS. Based on the analysis of MD simulation, the flexible region (amino acids 78-90) is not one of the most flexible regions (Additional file 1: Fig. S1). This means that the flexible region could be eliminated if only predicted by MD simulation. Therefore, it is important to use several predictive methods simultaneously for engineering the protein thermostability.

\section{Conclusions}

In this study, the flexible regions of trypsin were predicted by three methods (MD simulation, FlexPred, and FoldUnfold) and the highly flexible region were identified through the combination of three methods. Based on the above prediction, we modified this region by the method of truncation and acquired five variants. Compared with WT, the D9 variant showed a $5{ }^{\circ} \mathrm{C}, 5.8{ }^{\circ} \mathrm{C}$, and $4.5{ }^{\circ} \mathrm{C}$ increasement in $T_{\mathrm{opt}}, T_{50}^{10}$, and $T_{\mathrm{m}}$, respectively. The halflife value of D9 was $202.08 \mathrm{~min}, 46 \mathrm{~min}$ longer than that of WT. These results demonstrated that truncating the flexible regions could benefit the improvement of thermostability. In addition, this study provides an efficient method that could be applied to engineer other proteins for better thermostability.

\section{Methods}

\section{Analysis of flexible regions}

MD simulation was measured using the Gromacs package, version 5.0 with the Gromos force field (53A6). The initial structure was solvated in a cubic simulation box with a layer of water at least $1.1 \mathrm{~nm}$ from the protein surface. The whole system was minimized using the steepest descent method (1000 steps) in addition to the conjugate gradient method (5000 steps). Then two 100 ps position-restricted simulations were measured under NVT and NPT ensembles, respectively. Finally, a 10 ns MD simulation was performed at $300 \mathrm{~K}$. The values of RMSD (root mean square deviation) and RMSF (root mean square fluctuation) were calculated using g_rmsd and g_rmsf, respectively.

Similarly, the FoldUnfold and FlexPred were also used to predict the flexible regions. The FlexPred web server analyzes the flexibility of proteins using support vector machine (SVM). Moreover, the three-dimensional structure was used as an input for the two methods to predict flexible regions of proteins. The crystal structure of porcine trypsin (PDB ID: 4AN7) [40] was acquired from the Protein Data Bank and the structures of variants were constructed by homology modeling in the SWISSMODEL web server (http://www.swissmodel.expasy.org) [41]. The residue fluctuation profile of proteins was analyzed by CABS-flex server [42]. Visualization and analysis of structures were performed by PyMOL 2.7.6.

\section{Strains, plasmids, and chemicals}

Escherichia coli Top 10 (TransGen, Beijing, China) was used as the host strain for cloning. Pichia pastoris GS115 and the pPIC9K vector were from our laboratory collection. Pfu DNA polymerase and restriction endonucleases were purchased from Thermo Fisher Scientific (Waltham, USA). Bradford Protein Assay Kit (TIANGEN, Beijing, China) was used to determine the concentration of proteins. All other chemicals and reagents were analytical grade.

\section{Recombinant plasmid construction}

The gene sequence of the porcine trypsinogen (GenBank Accession No. CS583166.1) was synthesized (GENEWIZ 
Inc., Tianjin, China) and inserted into the vector pPIC9K to construct the plasmid pPIC9K-Try. Five variants (residues ${ }^{86-88} / \mathrm{D} 3$, residues ${ }^{84-88} / \mathrm{D} 5$, residues ${ }^{82-88} / \mathrm{D} 7$, residues $^{80-88} / \mathrm{D} 9$, and residues ${ }^{78-88} / \mathrm{D} 11$ ) were generated by deleting three amino acids, five amino acids, seven amino acids, nine amino acids and eleven amino acids, respectively, from the $\mathrm{N}$-terminal of Asp89 at the $\Omega$-loop region. The gene sequences of variants used in this study were achieved by overlapping extension PCR. The amplified PCR products and the PPIC9 $\mathrm{K}$ vector were digested with EcoRI and NotI, ligated, and then transformed into E. coli Top 10. The recombinant plasmids were confirmed by DNA sequencing (GENEWIZ Inc., Tianjin, China), and then transformed in P. pastoris GS115. All the primers used to acquire the variants in this study were shown in Additional file 1: Table S3.

\section{Expression and purification of trypsin variants}

The positive clones of the wild-type (WT) and variants were inoculated into shake flask containing $25 \mathrm{~mL}$ BMGY (buffered glycerol-complex) media and cultured at $30{ }^{\circ} \mathrm{C}$ with $250 \mathrm{rpm}$ shaking speed until the OD reached 2-6. Then centrifuged at $3000 \times g$ for 5 min to collect the cells and transferred into a $500 \mathrm{~mL}$ conical flask contained $100 \mathrm{~mL}$ of BMMY (buffered methanol-complex) medium to induce protein expression for $96 \mathrm{~h}$. As an inducer, methanol was added to a final concentration of $1 \%(\mathrm{v}: \mathrm{v})$ every $24 \mathrm{~h}$. The crude enzyme solutions were purified by a SP-Sepharose column (Bona INC., Jinan, China). Moreover, the protein was eluted using a $0-500 \mathrm{mM}$ sodium chloride gradient. The purification of WT and variants was performed by AKTA system (GE Healthcare, Sweden). The final concentration of enzymes was measured through Bradford method, and 15\% SDS-PAGE was used to certify the eluted protein [43].

\section{Enzyme activity assays}

The activity of trypsin was determined using Nabenzoyl L-arginine ethyl ester hydrochloride (BAEE) as a substrate, as described previously [44]. Initially, the assay was the trypsinogen activated by enterokinase. Furthermore, BAEE was hydrolyzed by trypsin to Nabenzoyl $\mathrm{L}$-arginine (BA). Trypsin reaction was conducted in a $3 \mathrm{~mL}$ of assay buffer $\left(67 \mathrm{mM} \mathrm{NaH} \mathrm{PO}_{4}\right.$ buffer, containing $0.25 \mathrm{mM}$ BAEE, $\mathrm{pH}$ 7.6). The change in absorbance at $253 \mathrm{~nm}$ was measured in a UV-765 PC spectrophotometer (Youke Co., Ltd, Shanghai, China). One unit (U) was defined as enzyme required for producing an $\Delta \mathrm{OD}_{253}$ of 0.001 per minute at $25^{\circ} \mathrm{C}$.

\section{Measurement of thermostability}

Digestion with trypsin is usually carried out at $20-40{ }^{\circ} \mathrm{C}$ [27]. It provides the possibility of carrying out digestions at higher temperatures if the porcine trypsin was found to be remarkably stable at $50{ }^{\circ} \mathrm{C}$. Thus, for the thermal stability assay, the purified trypsin $(200 \mu \mathrm{g} / \mathrm{mL}$ protein in $67 \mathrm{mM} \mathrm{NaH}_{2} \mathrm{PO}_{4}$ buffer, $\mathrm{pH}$ 7.6) were heat-treated at $50{ }^{\circ} \mathrm{C}$ for $30,60,90,120$, and $180 \mathrm{~min}$, and then cooled on ice for $30 \mathrm{~s}$. The enzyme activities were measured at $25{ }^{\circ} \mathrm{C}$, and the residual activity was recorded as the percentage of its initial activity. The first-order rate constant $\left(k_{\mathrm{d}}\right)$ was obtained by linear regression of $\ln$ (residual activity) versus the duration time. The half-time of WT and variants at $50{ }^{\circ} \mathrm{C}$ were calculated by the equation. All experiments data were duplicated three times.

The protein half-inactivation temperature $\left(T_{50}^{10}\right)$ was determined by measuring residual activity at different temperatures. The enzyme solutions were incubated at the temperature range of $25-85{ }^{\circ} \mathrm{C}$ for $10 \mathrm{~min}$ and then cooled on ice for $5 \mathrm{~min}$. Finally, the residual activity was determined at $25^{\circ} \mathrm{C}$ as described above. The value of $T_{50}^{10}$ was defined as the temperature when the enzyme lost half of its activity after the above treatment. The experiments were repeated three times.

\section{Thermoflour assay}

Melting temperatures of WT and variants were determined with the Thermoflour method [26, 45]. Samples containing $2.0 \mu \mathrm{M}$ protein and $5 \times$ SYPRO Orange (diluted from a $5000 \times$ stock supplied in DMSO) were prepared in sample buffer (50 mM HEPES, $0.5 \mathrm{mM}$ TCEP and $67 \mathrm{mM} \mathrm{NaH} \mathrm{PO}_{4}$ buffer, $\mathrm{pH}$ 7.6). Denaturation curves were determined in a LightCyder 480 Realtime PCR machine (Roche, Mannheim, Germany). The temperature was ranged from 25 to $95{ }^{\circ} \mathrm{C}$ at intervals of $0.5^{\circ} \mathrm{C}$. The wavelengths for excitation and emission were 465 and $580 \mathrm{~nm}$, respectively. All determinations were carried out in triplicate. The data were analyzed using a plug-in named LightCycler Thermal Shift Analysis (Roche, Mannheim, Germany) and melting temperature $\left(T_{\mathrm{m}}\right)$ was acquired by taking a negative first derivative plot.

\section{Measurement of optimum temperature}

The optimal temperature was assayed at various temperatures ranging from 25 to $85{ }^{\circ} \mathrm{C}$ at intervals of $5{ }^{\circ} \mathrm{C}$. For WT and variants, the optimal activity assayed was considered as $100 \%$. 


\section{Determination of kinetic parameters}

Kinetic parameters $\left(K_{\mathrm{m}}\right.$ and $\left.k_{\text {cat }}\right)$ were measured at various concentrations of substrate BAEE in $67 \mathrm{mM}$ $\mathrm{NaH}_{2} \mathrm{PO}_{4}$ buffer ( $\mathrm{pH}$ 7.6). The kinetic parameters were calculated by linear regression analysis of LineweaverBurk double-reciprocal plot. The measurements were performed by three times. All of measurements were performed by three times.

\section{Circular dichroism analysis}

Circular dichroism (CD) experiment was conducted on a J-810 spectrometer (Jasco, Japan). Samples $(0.2 \mathrm{mg} /$ $\mathrm{mL}$ ) in $10 \mathrm{mM}$ Tris- $\mathrm{HCl}$ buffer ( $\mathrm{pH} 8.0)$ were added to a $1 \mathrm{~mm}$ path length quartz cuvette for CD measurement. Spectra were collected with a scan speed of $200 \mathrm{~nm} / \mathrm{min}$ and a response time of $1 \mathrm{~s}$. The spectra data were monitored from 190 to $260 \mathrm{~nm}$ and were averages of three scans. The secondary structures of WT and variants were analyzed by the CDPro software (http://sites.bmb.colos tate.edu/sceeram/CDPro/).

\section{Fluorescence spectroscopy analysis}

The intrinsic fluorescence spectra of trypsin were detected on a Hitachi F-2500 Fluorescence Spectrophotometer (Hitachi, Japan) at a concentration of $10 \mu \mathrm{g} / \mathrm{mL}$. Samples were excited at $280 \mathrm{~nm}$, and the emission was recorded ranging from 300 to $400 \mathrm{~nm}$. The slit widths were $10 \mathrm{~nm}$. All experiments were carried out at room temperature $\left(25^{\circ} \mathrm{C}\right)$, while all required background corrections were made.

\section{Surface hydrophobicity analysis}

Protein surface hydrophobicity was measured using an 8-Anilino Naphthalene Sulfonic acid (ANS) fluorescent probe reported previously [46, 47]. The concentration of protein samples and the fluorescent probe ANS were $2 \mu \mathrm{M}$ and $30 \mu \mathrm{M}$, respectively. The excitation wavelength was $380 \mathrm{~nm}$, and the ANS emission spectra was monitored between 400 and $600 \mathrm{~nm}$. Measurements were determined by triplicates.

\section{Additional file}

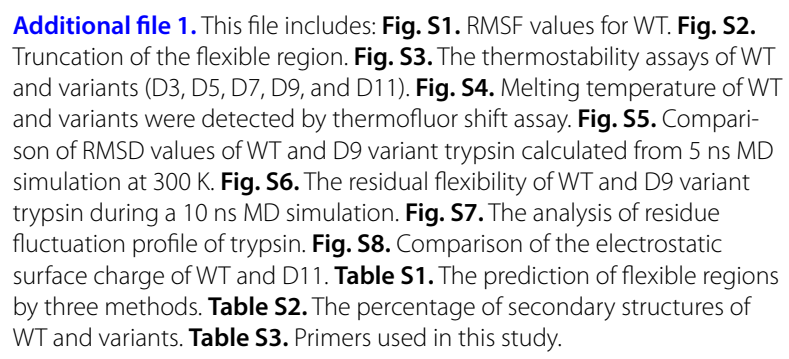

\section{Abbreviations}

RFS: rigidifying flexible sites; MD: molecular dynamic; RMSD: root mean square deviation; RMSF: root mean square fluctuation; SVM: support vector machine; BMGY: buffered glycerol-complex; BMMY: buffered methanol-complex; BAEE: Nabenzoyl L-arginine ethyl ester hydrochloride; TCEP: Tris(2-carboxyethyl) phosphine; ANS: 8-Anilino Naphthalene Sulfonic acid.

\section{Authors' contributions}

$\mathrm{LL}, \mathrm{YRG}$ and $\mathrm{HH}$ designed the experiments. $\mathrm{LL}$ and $\mathrm{KD}$ performed the experiments. LL, HRY and ZYW wrote the manuscript. All authors read and approved the final manuscript.

\section{Author details \\ ${ }^{1}$ Department of Biochemical Engineering, School of Chemical Engineering and Technology, Tianjin University, Tianjin 300350, China. ${ }^{2}$ Key Laboratory of System Bioengineering, Ministry of Education, Tianjin University, Tian- jin 300350, China. ${ }^{3}$ Collaborative Innovation Center of Chemical Science and Engineering, Tianjin 300350, China. ${ }^{4}$ Present Address: Department of Biochemical Engineering, University College London, Gordon Street, Lon- don WC1HOAH, UK.}

\section{Acknowledgements}

Not applicable.

\section{Competing interests}

The authors declare that they have no competing interests.

\section{Availability of data and materials}

All data generated or analyzed during this study are included in this published article.

\section{Consent for publication}

Not applicable.

\section{Ethics approval and consent to participate}

Not applicable.

\section{Funding}

This study was supported by the National Science and Technology Major Projects of China (Grant No. 2014ZX09508006-002-002).

\section{Publisher's Note}

Springer Nature remains neutral with regard to jurisdictional claims in published maps and institutional affiliations.

Received: 28 July 2018 Accepted: 19 October 2018

Published online: 25 October 2018

\section{References}

1. Rascon A, Seidl DS, Jaffe WG, Aizman A. Inhibition of trypsins and chymotrypsins from different animal species: a comparative study. Comp Biochem Physiol B Biochem Mol Biol. 1985;82:375-8.

2. Yao L, Man C, Zhao F, Qu X, Han X, Sun D, Jiang Y. Expression of bovine trypsin in Lactococcus lactis. Int Dairy J. 2010;20:806-9.

3. Leiros HKS, Brandsdal BO, Andersen OA, Os V, Leiros I, Helland R, Otlewski J, Willassen NP, Smalas AO. Trypsin specificity as elucidated by LIE calculations, $\mathrm{X}$-ray structures, and association constant measurements. Protein Sci. 2004;13:1056-70.

4. Finehout EJ, Cantor JR, Lee KH. Kinetic characterization of sequencing grade modified trypsin. Proteomics. 2005;5:2319-21.

5. Guo C, Liu Y, Yu HR, Du K, Gan YR, Huang H. A novel strategy for thermostability improvement of trypsin based on $\mathrm{N}$-glycosylation within the omega-loop region. J Microbiol Biotechnol. 2016;26:1163-72.

6. Pazhang M, Mehrnejad F, Pazhang Y, Falahati H, Chaparzadeh N. Effect of sorbitol and glycerol on the stability of trypsin and difference between their stabilization effects in the various solvents. Biotechnol Appl Biochem. 2016;63:206-13. 
7. Aslani E, Abri A, Pazhang M. Immobilization of trypsin onto $\mathrm{Fe}_{3} \mathrm{O}_{4} @ \mathrm{SiO}_{2}$ $-\mathrm{NH}_{2}$ and study of its activity and stability. Colloid Surf B Biointerfaces. 2018;170:553-62.

8. Bommarius AS, Paye MF. Stabilizing biocatalysts. Chem Soc Rev. 2013:42:6534-65.

9. $\mathrm{Yu} H$, Huang $\mathrm{H}$. Engineering proteins for thermostability through rigidifying flexible sites. Biotechnol Adv. 2014;32:308-15.

10. Rueda M, Ferrer-Costa C, Meyer T, Perez A, Camps J, Hospital A, Gelpi JL, Orozco M. A consensus view of protein dynamics. Proc Natl Acad Sci USA. 2007;104:796-801.

11. Kuznetsov IB. Simplified computational methods for the analysis of protein flexibility. Curr Protein Pept Sci. 2009;10:607-13.

12. Liu HL, Doleyres Y, Coutinho PM, Ford C, Reilly PJ. Replacement and deletion mutations in the catalytic domain and belt region of Aspergillus awamori glucoamylase to enhance thermostability. Protein Eng. 2000;13:655-9.

13. Damnjanovic J, Nakano H, Iwasaki Y. Deletion of a dynamic surface loop improves stability and changes kinetic behavior of phosphatidylinositol-synthesizing Streptomyces phospholipase D. Biotechnol Bioeng. 2014:111:674-82.

14. Lu XY, Liu S, Feng Y, Rao SQ, Zhou XM, Wang M, Du GC, Chen J. Enhanced thermal stability of Pseudomonas aeruginosa lipoxygenase through modification of two highly flexible regions. Appl Microbiol Biotechnol. 2014;98:1663-9.

15. Ban XF, Liu YT, Zhang YZ, Gu ZB, Li CM, Cheng L, Hong Y, Dhoble AS, Li ZF. Thermostabilization of a thermophilic 1,4-alpha-glucan branching enzyme through C-terminal truncation. Int J Biol Macromol. 2018;107:1510-8.

16. Zhou HY, Yang WJ, Tian Y, Peng HH, Wu YY. N-terminal truncation contributed to increasing thermal stability of mannanase Man1312 without activity loss. J Sci Food Agric. 2016;96:1390-5.

17. Nestl BM, Hauer B. Engineering of flexible loops in enzymes. ACS Catal. 2014:4:3201-11

18. Fetrow JS. Omega loops: nonregular secondary structures significant in protein function and stability. FASEB J. 1995;9:708-17.

19. Siddiqui KS. Defying the activity-stability trade-off in enzymes: taking advantage of entropy to enhance activity and thermostability. Crit Rev Biotechnol. 2017;37:309-22.

20. Thompson MJ, Eisenberg D. Transproteomic evidence of loopdeletion mechanism for enhancing protein thermostability. J Mol Biol. 1999;292:946.

21. Boone CD, Rasi V, Tu C, McKenna R. Structural and catalytic effects of proline substitution and surface loop deletion in the extended active site of human carbonic anhydrase II. FEBS J. 2015;282:1445-7.

22. Yedavalli P, Rao NM. Engineering the loops in a lipase for stability in DMSO. Protein Eng Des Sel. 2013;26:317-24.

23. Yu HR, Yan YH, Zhang C, Dalby PA. Two strategies to engineer flexible loops for improved enzyme thermostability. Sci Rep. 2017;7:15.

24. Herbert C, Schieborr U, Saxena K, Juraszek J, De Smet F, Alcouffe C, Bianciotto M, Saladino G, Sibrac D, Kudlinzki D, et al. Molecular mechanism of SSR128129E, an extracellularly acting, small-molecule, allosteric inhibitor of FGF receptor signaling. Cancer Cell. 2013;23:489-501.

25. Polizzi KM, Bommarius AS, Broering JM, Chaparro-Riggers JF. Stability of biocatalysts. Curr Opin Chem Biol. 2007;11:220-5.

26. Ericsson UB, Hallberg BM, DeTitta GT, Dekker N, Nordlund P. Thermofluorbased high-throughput stability optimization of proteins for structural studies. Anal Biochem. 2006;357:289-98.

27. Pham VT, Ewing E, Kaplan H, Choma C, Hefford MA. Glycation improves the thermostability of trypsin and chymotrypsin. Biotechnol Bioeng. 2008:101:452-9.

28. Sun J, Yang L, Jiang MM, Shi Y, Xu B, Ma HL. Stability and activity of immobilized trypsin on carboxymethyl chitosan-functionalized magnetic nanoparticles cross-linked with carbodiimide and glutaraldehyde. J Chromatogr B. 2017;1054:57-63.
29. Niu C, Zhu L, Xu X, Li Q. Rational design of thermostability in bacterial 1,3-1,4-beta-glucanases through spatial compartmentalization of mutational hotspots. Appl Microbiol Biotechnol. 2017;101:1085-97.

30. Pack SP, Yoo YJ. Protein thermostability: structure-based difference of amino acid between thermophilic and mesophilic proteins. J Biotechnol. 2004;111:269-77.

31. Machius M, Declerck N, Huber R, Wiegand G. Kinetic stabilization of Bacillus licheniformis alpha-amylase through introduction of hydrophobic residues at the surface. J Biol Chem. 2003:278:11546-53.

32. Fang Z, Zhang J, Liu BH, Du GC, Chen J. Insight into the substrate specificity of keratinase KerSMD from Stenotrophomonas maltophilia by site-directed mutagenesis studies in the S1 pocket. RSC Adv. 2015;5:74953-60.

33. Gao HF, Li CJ, Bandikari R, Liu ZD, Hu N, Yong Q. A novel cold-adapted esterase from Enterobacter cloacae: characterization and improvement of its activity and thermostability via the site of Tyr193Cys. Microb Cell Fact. 2018;17:11

34. Kheirollahi A, Khajeh K, Golestani A. Rigidifying flexible sites: an approach to improve stability of chondroitinase ABC I. Int J Biol Macromol. 2017:97:270-8.

35. Liskova V, Bednar D, Prudnikova T, Rezacova P, Koudelakova T, Sebestova E, Smatanova IK, Brezovsky J, Chaloupkova R, Damborsky J. Balancing the stability-activity trade-off by fine-tuning dehalogenase access tunnels. ChemCatChem. 2015;7:648-59.

36. Vidya J, Ushasree MV, Pandey A. Effect of surface charge alteration on stability of L-asparaginase II from Escherichia sp. Enzyme Microb Technol. 2014;56:15-9.

37. Deng ZM, Yang HQ, Shin HD, Li JH, Liu L. Structure-based rational design and introduction of arginines on the surface of an alkaline alpha-amylase from Alkalimonas amylolytica for improved thermostability. Appl Microbiol Biotechnol. 2014:98:8937-45.

38. Reich S, Kress N, Nest BM, Hauer B. Variations in the stability of NCR ene reductase by rational enzyme loop modulation. J Struct Biol. 2014;185:228-33.

39. Zhang $X F$, Yang GY, Zhang $Y$, Xie $Y$, Withers SG, Feng $Y$. A general and efficient strategy for generating the stable enzymes. Sci Rep. 2016;6:12.

40. Patil DN, Chaudhary A, Sharma AK, Tomar S, Kumar P. Structural basis for dual inhibitory role of tamarind Kunitz inhibitor (TKI) against factor Xa and trypsin. FEBS J. 2012;279:4547-64.

41. Waterhouse A, Bertoni M, Bienert S, Studer G, Tauriello G, Gumienny R, Heer FT, de Beer TAP, Rempfer C, Bordoli L, et al. SWISS-MODEL: homology modelling of protein structures and complexes. Nucleic Acids Res. 2018;46:W296-W303.

42. Jamroz M, Kolinski A, Kmiecik S. CABS-flex: server for fast simulation of protein structure fluctuations. Nucleic Acids Res. 2013;41:W427-31.

43. Bradford MM. A rapid and sensitive method for the quantitation of microgram quantities of protein utilizing the principle of protein-dye binding. Anal Biochem. 1976;72:248-54.

44. Bougatef A, Souissi N, Fakhfakh N, Ellouz-Triki Y, Nasri M. Purification and characterization of trypsin from the viscera of sardine (Sardina pilchardus). Food Chem. 2007:102:343-50.

45. de Araujo ED, Manaswiyoungkul P, Israelian J, Park J, Yuen K, Farhangi S, Berger-Becvar A, Abu-Jazar L, Gunning PT. High-throughput thermofluorbased assays for inhibitor screening of STAT SH2 domains. J Pharm Biomed Anal. 2017;143:159-67.

46. Kato A, Nakai S. Hydrophobicity determined by a fluorescence probe method and its correlation with surface properties of proteins. Biochim Biophys Acta. 1980;624:13-20.

47. Puppo C, Chapleau N, Speroni F, de Lamballerie-Anton M, Michel F, Anon C, Anton M. Physicochemical modifications of high-pressure-treated soybean protein isolates. J Agric Food Chem. 2004;52:1564-71. 